\title{
Physico-chemical Assessment and Rebauidioside A. Productively of Natural Sweeteners (Stevia Rebaudiana Bertoni)
}

\author{
Mohammed Abdalbasit A. Gasmalla, ${ }^{1,2}$, Ruijin Yang ${ }^{1, *}$, Abubakr Musa ${ }^{1}$, Xiao Hua ${ }^{1}$, Wenbin Zhang ${ }^{1}$ \\ ${ }^{1}$ State Key Laboratory of Food Science and Technology, School of Food Science and Technology, Jiangnan University, Wuxi 214122, \\ PR China \\ ${ }^{2}$ Department of Nutrition \& Food technology, Faculty of Science and Technology, Omdurman Islamic University, P.O. Box 382, \\ 14415, Khartoum, Sudan \\ *Corresponding author: yrj@jiangnan.edu.cn
}

Received April 14, 2014; Revised May 12, 2014; Accepted May 15, 2014

\begin{abstract}
Stevia rebaudian Bertoni, belonging to the Compositae family, is a sweet herb contains diterpene glycosides, namely, stevioside, rebaudiosides A-F, steviolbioside, and dulcoside A, which are responsible for the typical sweet taste. Stevia (Stevia rebaudian Bertoni) leaves were analyzed for their physiochemical properties, chemical composition and microbiological contamination in addition to rebauidioside A productively. The carbohydrates content was $63.10 \%$, while the moisture, fiber, protein, ash, fat and reducing sugar contents were $10.73 \%, 5.03 \%, 13.68 \%, 12.06 \%, 6.13 \%$ and $4.50 \%$, respectively. Anti-nutritional value (tannin) was $5.43 \%$. The total soluble substance was $17.03 \%$. The Stevia leaves showed a good antimicrobial agent for all tested bacterial groups including Coliforms, Staphylococcus. Rebauidioside A was extracted and purified from the dried Stevia leaves by ultrasonic-assisted extraction method. The optimum extraction time was 6 min in which the maximum rebauidioside A content was obtained ( $32.79 \mathrm{~g} / 100 \mathrm{~g})$. Results show that particle size of sample treated for 6 min is bigger than those for 12, 18 and 24 min. Application of ultrasound-assisted extraction on the Stevia plant substantially affects the Color, and particle size of the stevia leaf extract and rebauidioside A yield.
\end{abstract}

Keywords: color, particle size, Physico-chemical, microbial analysis, Extraction, stevia, Rebaudioside A

Cite This Article: Mohammed Abdalbasit A. Gasmalla, Ruijin Yang, Abubakr Musa, Xiao Hua, and Wenbin Zhang, "Physico-chemical Assessment and Rebauidioside A. Productively of Natural Sweeteners (Stevia Rebaudiana Bertoni)." Journal of Food and Nutrition Research, vol. 2, no. 5 (2014): 209-214. doi: 10.12691/jfnr2-5-1.

\section{Introduction}

Stevioside (S) and rebaudioside A (RA) are two major steviol glycosides in the extracts produced from the leaves of Stevia rebaudiana Bertoni [1]. The stevia extracts, recently approved by the US FDA as GRAS (generally recognized as safe), have been widely used as a natural sweetener or a dietary supplement in various food and beverage products. Stevioside tastes 250-300 times sweeter than sucrose but exhibits a significant bitter aftertaste [2]. In order to increase the yield, several intensification techniques like ultrasonic waves, supercritical fluids or microwaves were associated with extraction of plant's compounds to improve the yield and quality of extracted products [3]. Stevia has been used as a low-calorie sweetener for years in South America, Asia, Japan, and China, and in some countries of the European Union. Currently, Japan and Korea are the largest markets for stevia. However, China is the largest stevia grower in the world, and about $80 \%$ of their product is exported. Stevia is also being cultivated by Indian farmers since the last decade, and is used as raw dry leaf or as a processed sweetener. In Brazil, Korea and Japan, stevia leaves and highly refined extracts are used as a low-calorie sweetener $[4,5]$. According to the International Diabetes Federation (IDF) and the Madras Diabetes Research Foundation, India had 62.4 million people with type 2 diabetesin 2011, compared with 50.8 million in 2010 [6]. In the USA, powdered stevia leaves and refined extracts from leaves have been used as a dietary supplement since 1995 [7]. Therefore, the worldwide demand for Stevia rebaudiana is expected to increase. The leaf yield and concentration of active compounds depend on the cultivar, growing conditions and agronomic practices.

The increasing demand for herbal care for diabetes calls for intense farming of Stevia rebaudiana to increase the production of its low-calorie sweetening glycosides. Studies reveal that the content of these glycosides, especially stevioside, greatly depends on the total biomass produced, which in turn depends on agricultural practices for cultivation of Stevia plants [7]. In pursuit of high production of glycosides, researchers have adopted modern agro-techniques (Das et al. 2008), water management [8] and fertiliser applications [9]. In addition, 
tissue culture techniques and cultivation of Stevia plants in bioreactors have also been tested [10]. However, in the above techniques, the main shortcomings are the high costs and low in-field practicability. For example, chemical fertilisers constitute a few mineral nutrients and create an imbalance in the whole mineral pattern of the plant body by hindering the uptake of other useful nutrients [11]. Nowadays, due to the growth of the health food industry reduction of sucrose content of food products by full or partial replacement of sucrose using alternative sweeteners have become a viable option for producing low calorie/zero calorie foods. Low calorie food products of good quality can be made by incorporating combinations of non-caloric and carbohydrate sweeteners [12].

In recent years, ultrasonic treatment has found numerous applications in the food industry [13]. Ultrasound can be used either as a diagnostic or treatment tool or as a source of energy. For each of these applications, different ultrasound frequency ranges should be used [14]. Power ultrasound has additional potential applications, including enzyme inhibition, hydrogenation of oils, crystallisation control, extraction of protein and enzymes, inactivation of microorganisms and improvement of heat and mass transfer $[15,16]$. However, scaling up these potential applications requires more research. The major mechanism of power ultrasound is the generation and subsequent destruction of cavitation bubbles. When ultrasonic waves propagate into a medium, a series of compression and rarefaction waves are induced in the molecules of the medium through which it passes. During these cycles, small bubbles form and expand due to gas diffusion $[17,18]$. The aim of the present work is to study the effect of extraction time by ultrasound on the color, particle size and rebaudioside A content in Stevia rebaudiana Bertoni dispersion extracted by water.

\section{Materials and Methods}

\subsection{Materials}

Green Stevia leaves were obtained from the Yancheng Xiaguang Stevioside Trading Company (Jiangsu, China), a high-speed blender (25000/min), type WK - 1000A (Qingzhou Jing cheng Machinery Co., LTD- Shandong China), pH-meter FE20 Mettler-Toledo Instruments (Shanghai, China), Centrifuge CT14D Shanghai Techomp Bio-Equipment LTD (Shanghai, China).Sodium hydroxide( $\mathrm{NaOH})$, Sluphuric acid $\left(\mathrm{H}_{2} \mathrm{SO}_{4}\right)$, Hydrochloric acid (HCL), solvents and others chemical were obtained from Sigma Chemical Co. (Shanghai, China). A Minolta spectrophotometer (CR-400, Konica Minolta Sensing, Tokyo, Japan). Microtrac Bluewave S3500 SIA (Microotrac Inc. FL., USA) with Microtrac Flex 10.5.4 software

\subsection{Preparation of Stevia Leaves}

The fresh green leaves of Stevia rebaudiana Bertoni (Figure 1 a) were allowed to dry using direct sun light for about 5 days. The dried leaves were then blended to powder using a high-speed blender (25000/min) (Figure 1 b). The powder samples were stored in polyethylene bags at $4^{\circ} \mathrm{C}$ until used [19]. (a)

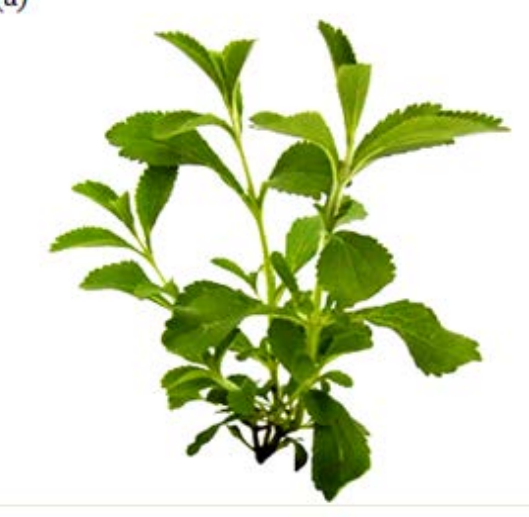

(b)

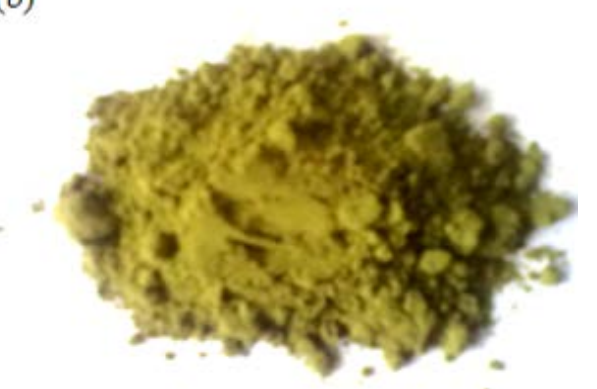

Figure 1. (a): The fresh green leaves of stevia rebaudiana Bertoni; (b): The dried leaves after blended to powder

\subsection{Ultrasound Apparatus}

An ultrasonic generator (JY98-III DN, Nanjing FeiQi Industry \&Trade Co., LTD. Nanjing- China) was used for extraction. The immersion stainless steel transducer was of the horn-type with a length of $300 \mathrm{~mm}$ and a diameter of $20 \mathrm{~mm}$. delivering a maximum power of $1200 \mathrm{~W}$ at 20 $\mathrm{kHz}$ it was equipped with a thermometer to measure the reaction temperature and inserted in the slurry to introduce ultrasound field. A circulating water bath (HH-2 Guohua Wiring Company, Shanghai, China) was adopted to keep the reaction temperature at a constant. A magnetic stirrer was used to suspend the particles in the reactor and speed up heat transfer.

\subsection{Physico -chemical Analysis of Stevia Leaves}

The prepared samples were analyzed for moisture, protein, fat, crude fiber and ash according to the methods described by the AOAC [20]. The carbohydrate content was determined by subtracting the total crude protein, crude fiber, ash and fat from the total dry weight (100 g) of the food sample differences. Reducing sugars content were determined according to a previous study [21]. The analysis of tannins content was performed according to International Pharmacopoeia and AOAC [20] method. A refractometer was used to determine the total soluble substance of the samples according to the method reported by Kimball [22].

\subsection{Microbiological Analysis}

All samples were analyzed for total viable count, moulds and yeasts, coliforms and Staphylococcus aureus. Stevia leaf powder (10 g) were taken aseptically and diluted with $90 \mathrm{~mL}$ of $0.1 \%$ sterile peptone water. The samples were homogenized by a stomacher at high speed 
for 2 min. Serial dilutions $\left(10^{-1}-10^{-5}\right)$ were made in tubes (1.0 mL with $9 \mathrm{~mL}$ of $0.1 \%$ peptone water). The plates were incubated for $48 \mathrm{~h}$ at $37^{\circ} \mathrm{C}$, while $72 \mathrm{~h}$ at $28^{\circ} \mathrm{C}$ for yeast and moulds and the number of colony forming units per $\mathrm{mL}\left(\mathrm{CFU} \mathrm{g}{ }^{-1}\right)$ of Stevia leaves was determined.

\subsection{Color Measurement}

Hunter $\mathrm{a}, \mathrm{b}$ and $\mathrm{L}$ parameters of stevia extract were determined with a Minolta spectrophotometer (CR-400, Konica Minolta Sensing, Tokyo, Japan) in the reflection mode. The instrument was standardized with a white ceramic plate $(\mathrm{L}=99.50, \mathrm{a}=-0.01, \mathrm{~b}=-0.12)$. The hue $(\mathrm{H})$, chroma (C) and browning index (BI) were calculated as follows:

$$
\begin{aligned}
& \mathrm{H}=\tan ^{-1}[\mathrm{~b} / \mathrm{a}](\mathrm{i}) \\
& \mathrm{C}=\mathrm{a}^{2}+\mathrm{b}^{2}(\mathrm{ii}) \\
& \mathrm{BI}=[100(\mathrm{X}-0.31)] / 0.172 \text { (iii) } \\
& \text { Where: } \\
& \mathrm{X}=(\mathrm{a}+1.75 \mathrm{~L}) /(5.645 \mathrm{~L}+\mathrm{a}-3.012 \mathrm{~b}) \text { (iv) }
\end{aligned}
$$

The browning index (BI) represents the purity of brown color and is reported as an important parameter in processes where enzymatic or non enzymatic browning takes place $[23,24,25]$.

\subsection{Particle Size Analysis}

The particle size distributions of stevia extract were determined at room temperature with a Microtrac Blue wave S3500 SIA (Microotrac Inc. FL., USA) with Microtrac Flex 10.5.4 software.

\subsection{Extraction and Purification of Rebaudioside A}

Dry and ground stevia leaves samples (10 g) was extracted in $100 \mathrm{~mL}$ of water, with frequent stirring $(\mathrm{pH}$ value was controlled with $0.01 \mathrm{M} \mathrm{pH} 7$ sodium phosphate). The sample was put in a $100 \mathrm{~mL}$ cylindrical glass reactor of standard geometry thoroughly mixed and the ultrasound generator probe inserted immediately. The tip of the probe was immersed about $1.5 \mathrm{~cm}$ into the slurry. The sonication experiments were carried out at a frequency of $20 \mathrm{kHz}$ and rated power output of $360 \mathrm{~W}$. The solution was processed with the ultrasound radiation for different irradiation times (6, 12, 18 and $24 \mathrm{~min}$ ) while the temperature inside was kept constant at $30^{\circ} \mathrm{C}$. The extract solution was centrifuged and filtered off through $0.45 \mu \mathrm{m}$ microporous membrane; the filtrate was taken for total rebaudioside A content analysis. The extraction yield of total rebaudioside A content was defined by the HPLC analysis.

\subsection{Determination of Rebaudioside A by HPLC}

A stock solution of $1 \mathrm{~g}$ rebaudioside A (Standard) In 25 $\mathrm{ml}$ of water was prepared. Solutions of 25, 50, 100, 150, 200, 250, and $300 \mu \mathrm{g} / \mathrm{L}$ were made by transferring an aliquot from stock solution and the volume was made with water in each case. Further standard solutions were prepared freshly each day by appropriate dilution of stock solution with water for intraday as well as interday analysis. $200 \mu \mathrm{g} / \mathrm{L}$ of solvent extract was accurately weighed and transferred to a $25 \mathrm{~mL}$ volumetric flask and the volume was made by distilled water. Then $10 \mu \mathrm{L}$ of the stock solution was subjected to HPLC analysis and the concentration of rebaudioside $\mathrm{A}$ was calculated based on the calibration curve equation $\left(\mathrm{y}=36781 \mathrm{x}+2887.7, \mathrm{R}^{2}=\right.$ 0.9993).

\subsection{Statistical Analysis}

All experiments described above were made in triplicate for each sample. The data presented were the means and standard deviations of each experiment. The experimental data were analyzed using the ANOVA and Duncan's multiple range tests by the SPSS 17.0 (SPSS Inc., Chicago, USA) software. Unless otherwise noted in the text, a $\mathrm{P} \leq 0.05$ level was used where values were considered as being significantly different.

\section{Results and Discussion}

\subsection{Physico-chemical Analysis of Stevia Leaves}

The proximate chemical composition of dried Stevia rebaudiana leaf is shown in Table 1 . The results using sun drying exhibited significant ( $\mathrm{p} \leq 0.05$ ) values in moisture, ash and protein contents of stevia leaves. On the other hand, the study showed that both fiber and fat contents were not significant $(\mathrm{p} \leq 0.05)$ in the dried leaves. The tannin content of Stevia leaves obtained is presented in Table 1. The composition data indicate that the dried Stevia rebaudiana leaf has higher moisture content due to the intensity of sun heat. In our work ash content was similar to reported by Mishra et al [26]. Tadhani and Subhash [27] reported a slightly higher amount of ash content and substantial amount of crude fiber [28,29]. Our study have shown the more protein content as compare to Kaushik et al [29] and Abou-Arab et al [30]; whereas, the fat content value was higher than that reported by Serio [31], and a valuable carbohydrate was found. Gisleine et al [32] reported that protein, fat, crude fiber, ash, and carbohydrates were present in dried sample. Our results demonstrate the same figures in Table 1.

Table. 1. Physico-chemical and microbiological parameters of Stevia rebaudiana bertoni leaves

\begin{tabular}{|c|c|}
\hline \multicolumn{2}{|c|}{ Physico-chemical properties } \\
\hline Content & Value (\%) \\
\hline $\mathrm{pH}$ & 5.96 \\
\hline Moisture & $10.73 \pm 1.33$ \\
\hline Fiber & $5.03 \pm 0.16$ \\
\hline Protein & $13.68 \pm 1.86$ \\
\hline Fat & $6.13 \pm 0.63$ \\
\hline Ash & $12.06 \pm 1.33$ \\
\hline Carbohydrate & $63.10 \pm 1.20$ \\
\hline Tannin & $5.43 \pm 0.89$ \\
\hline Reducing sugar & $4.50 \pm 0.10$ \\
\hline Total soluble substance & $17.03 \pm 0.44$ \\
\hline Microbiology Analysis \\
\hline Total bacteria & ND \\
\hline Mould and Yeast & ND \\
\hline Coliforms & ND \\
\hline Staphylococcus & ND \\
\hline
\end{tabular}

All values are means of triplicate determinations \pm standard deviation (SD).

ND: not detected.

Stevia leaves are a good source of nutritional values . It has been used as a substitute for sugar in place of pure stevioside in different food preparations and its high ash 
content indicates that the stevia leaves are good source of inorganic minerals $[28,29]$ It was also found that the tannins value is lower than that of Rai [28] who found $7.8 \%$.Tannins possessing useful properties such as antioxidant, anti-apoptosis, anti-aging, anti carcinogenic, anti-inflammatory, as well as anti atherosclerosis and cardiovascular protection [33].

\subsection{Microbiological Analysis}

The study on microbial analysis of Stevia rebaudiana fresh leaf after dried by sun was conducted mainly to assess the evolution of the microbial contamination of leaves during its preparation process and to observe the use of hygienic practices which may reduce incidences of cross contamination in the food industry. The results of microbial analysis showed no contamination detected of leaves by all tested bacterial groups and yeast and moulds as shown in Table 1 . The study confirms the possible antimicrobial potentiality of the leaf extract of Stevia rebaudiana

\subsection{Color Measurement}

Table 2. Color analysis of Stevia rebaudiana bertoni dispersions through ultrasonic treatment

\begin{tabular}{|c|c|c|c|c|c|c|}
\hline Time (min) & $\mathrm{L}$ & a & $\mathrm{b}$ & Hue & Chroma & Browing Index \\
\hline 6 & 27.53 & 1.54 & 2.55 & 58.87 & 2.98 & 13.41 \\
\hline 12 & 27.74 & 0.89 & 2.67 & 71.57 & 2.81 & 12.09 \\
\hline 18 & 26.16 & -0.17 & 0.57 & 73.39 & 0.59 & 1.66 \\
\hline 24 & 28.64 & -0.13 & 3.06 & 87.57 & 3.06 & 10.57 \\
\hline
\end{tabular}

\subsection{Particle Size Analysis}

Various conditions for the preparation of stevia leaf extract particles are summarized in Table 3. Sonication was applied for 6, 12, 18 and 24 min with sonication power $360 \mathrm{~W}$. Results show that the particle size for sample treated for 6 min is bigger than that for 12, 18 and 24 min, which means that ultrasonic treatment at constant power, with increasing time, caused a decrease in particle size distribution in the stevia leaves extract

After $24 \mathrm{~min}$ of ultrasonic treatment, the median increased from $(95.62 \mu \mathrm{m})$ at $6 \mathrm{~min}$ to $(101.5 \mu \mathrm{m})$ at 12 min and then decreased to $(98.48 \mu \mathrm{m})$ and $(91.99 \mu \mathrm{m})$ when using ultrasonic time of $18 \mathrm{~min}$ and $24 \mathrm{~min}$ respectively. This shows disruption of large particles, resulting in smaller particles with a narrower particle size distribution. After sonication time of 6, 12, 18 and 24 min, D10 dramatically increased and decreased, while D90 decreased after all treatments (Table 3).

Table 3. Particle size analysis of Stevia rebaudiana bertoni dispersions through ultrasonic treatment

\begin{tabular}{|c|c|c|c|c|c|}
\hline Time [min] & Mean [um] & Median & Mode & $\mathrm{D}_{10}[\mathrm{um}]$ & $\mathrm{D}_{90}[\mathrm{um}]$ \\
\hline 6 & 125.23 & 95.62 & 221.97 & 8.28 & 265.97 \\
\hline 12 & 107.9 & 101.5 & 104.6 & 67.70 & 156.5 \\
\hline 18 & 98.14 & 98.48 & 119.45 & 91.42 & 145.6 \\
\hline 24 & 91.35 & 91.99 & 104.6 & 24.88 & 68.25 \\
\hline
\end{tabular}

This indicates that various of sonication time lead to different particle size diameters.

The most important alteration is the ratio of soluble to insoluble components. The ratio of soluble to insoluble components is different in various weights of Stevia leaves $[35,36]$ as reported that the insoluble part that is less
After sample treated with ultrasonic treatment, $\mathrm{b}^{*}$ values (1.76) gradually changed toward a positive direction in all samples. In addition, $a^{*}$ values shifted from 1.26 to a negative direction except sample treated for 6 min has $\mathrm{a}^{*}$ value (1.54). It was a different direction in color change compared to the color changes observed in stevia extract. A color shift toward negative $\mathrm{b}^{*}$ and $\mathrm{a}^{*}$ directions indicate less red in stevia sonicated dispersion. The majority of samples showed slight decreases in $\mathrm{L}^{*}$ value after sonication, which indicates a lightening of solution surface color. A small increase in $\mathrm{L}^{*}$ value for stevia extract can probably be attributed to partial precipitation of unstable, suspended particles in solution as described [34]. The conditions used for sonication of stevia extract are listed in Table 2. Significant changes in color of stevia extract were observed during sonication. Untreated samples had lightness (L), yellowness (a) and redness (b) values of 26.95, 1.26, and 1.76 respectively. Three characteristics were significantly influenced by ultrasound, namely Hue, Chrome and Browning Index. Sonication time affected the color parameters of the stevia leaves solutions (Table 2). The L value for each sonication time, the initial color parameters were Significant different $(\mathrm{p} \leq 0.05)$. branched produces natural aggregates. It seems that under ultrasonic treatment, soluble and insoluble components change in different ways and the new aggregate formation depends on the chain size and the total portion of the insoluble component.

During sonoprocessing of the soluble component, the branches were first to be influenced and broken up. This probable phenomenon can result in the formation of unbranched backbones, which in turn can form new aggregates. Although these aggregates can decrease the particle size distribution to some extent, they are smaller than insoluble component aggregates. This trend continues until the chains that produced the aggregates were not able to produce larger aggregates anymore due to continuous separation of monomers; the chains become too small, and the trend reverses. The phenomena described above were observed in this study in the particle size distribution analysis of stevia leaves extract. However, the reduction in particle size distribution is clear, as shown in Table 3.

\subsection{Effect of Sonication on the Rebauidioside A Extraction Yield}

As a result, water was tested in ultrasonication, the contents of rebaudioside A extracted from stevia leaves were significant $(\mathrm{p} \leq 0.05)$ and the impact of extraction time on the rebauidioside A productively was demonstrated in (Table 4). Among the extracts tested, 6 min showed the highest amount (32.79 g/100 g) of rebaudioside A obtained by water combining with ultrasound-assisted extraction analyzed by HighPerformance Liquid Chromatography (HPLC) under 
analytical conditions, the typical retention time ( $\mathrm{R} \mathrm{t}$ ) of rebauidioside A was 3.35 min (Figure 3 ) comparing with standard rebauidioside A (Figure 2).

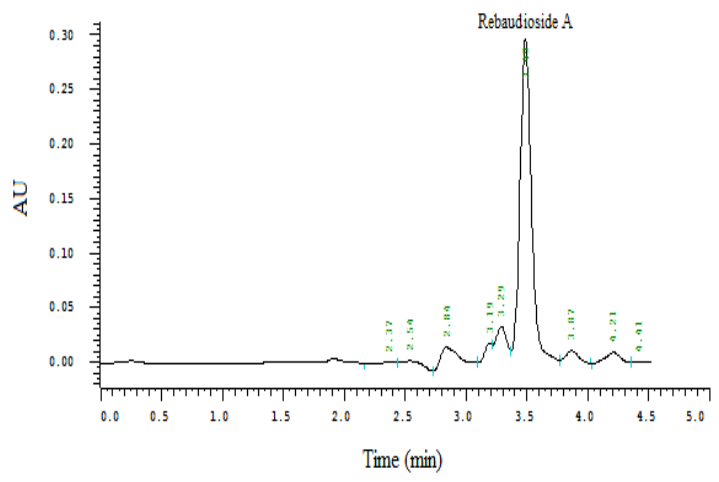

Figure 2. HPLC Chromatogram of rebaudioside A from standard solution, Rt of rebaudioside A was 3.49 min under separation acetonitrile:water $(65: 35 \mathrm{v} / \mathrm{v})$ as the elusion solvent at flow rate of 1 $\mathrm{ml} / \mathrm{min}$ and the detection wavelength $210 \mathrm{~nm}$, column was Agilent C18 $(25 \mathrm{~cm} \times 4.6 \mathrm{~mm}$ I.D., $10 \mu \mathrm{l})$

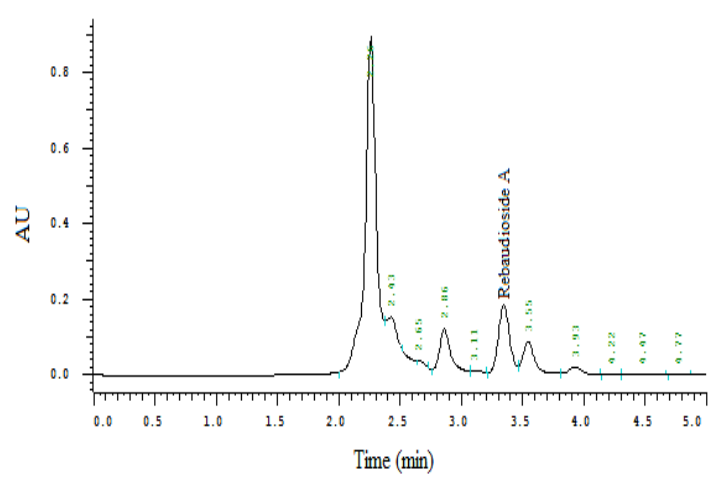

Figure 3. HPLC Chromatogram of rebaudioside A (Rt= $3.4 \mathrm{~min})$ of sample extract obtained with ultrasonic at power $360 \mathrm{~W}$ for 6 min under separation acetonitrile:water $(65: 35 \mathrm{v} / \mathrm{v})$ as the elusion solvent at flow rate of $1 \mathrm{ml} / \mathrm{min}$ and the detection wavelength $210 \mathrm{~nm}$, column was Agilent C18 $(25 \mathrm{~cm} \times 4.6 \mathrm{~mm}$ I.D., $10 \mu \mathrm{l})$.

Ultrasonic power and extraction time are two important factors that affect the extraction of total steviolglycoside, the extraction yield was decreased with the sonication time from 6 min to 24 min while the total soluble solids increase. It also resulted in the changes of some important physical characteristics of water poor phase, such as polarity, viscosity and surface tension. This result may have a significant effect on the sonication activity and the partition behavior of rebauidioside A in aqueous system. Where, the extraction yield decreased slightly with the change of sonication time as shown in Table 4.

Table 4. The effect of sonication on the Rebauidioside A extraction yield

\begin{tabular}{|c|c|c|c|}
\hline $\begin{array}{c}\text { Sonication } \\
\text { Time (min) }\end{array}$ & $\begin{array}{c}\text { Sonication } \\
\text { Power (W) }\end{array}$ & $\begin{array}{c}\text { Total soluble } \\
\text { substance }(\%)\end{array}$ & $\begin{array}{c}\text { Rebauidioside A } \\
(\mathrm{g} / 100 \mathrm{~g})\end{array}$ \\
\hline 6 & 360 & $11.16 \pm 0.67^{\mathrm{a}}$ & $32.79 \pm 1.57^{\mathrm{a}}$ \\
\hline 12 & 360 & $12.23 \pm 1.04^{\mathrm{a}}$ & $30.45 \pm 2.23^{\mathrm{b}}$ \\
\hline 18 & 360 & $13.37 \pm 0.75^{\mathrm{a}}$ & $28.66 \pm 2.26^{\mathrm{c}}$ \\
\hline 24 & 360 & $18.00 \pm 0.45^{\mathrm{b}}$ & $28.72 \pm 1.68^{\mathrm{c}}$ \\
\hline
\end{tabular}

All values are means of triplicate determinations \pm standard deviation (SD).

Mean values in the same column with different letters are significantly different $(\mathrm{p} \leq 0.05)$.

Water was tested to extract rebaudioside A from dried leaves of Stevia rebaudiana Bertoni. Water proved to be beneficial, dissolve the constituents more effectively thus, leading to improve of the extraction yield. The concentration of the extracted rebaudioside $\mathrm{A}$ into the liquid phase rises faster to the equilibrium value, decreasing this way the extraction driving force. Our data revealed that the extraction efficiency obtained with ultrasonic extraction was higher than maceration extraction as reported by Liu et al for extraction rebaudioside $\mathrm{A}$ [37].

\section{Conclusion}

Stevia rebaudiana Bertoni leaves generally have an image as healthy sweetener and form an important part of nutritious diet. This study revealed that Stevia leaves are a good source of carbohydrates, protein, crude fiber, which are valuable for human nutrition. Physico-chemical characteristics indicate that Stevia leaves could be applied as substitute of sucrose in different food products. No microbial contamination detected in throughout of this study. Therefore, the foods containing Stevia could be use without any worry about food borne disease and can be consume as antimicrobial agent in near future. The particle-size reduction by ultrasound is a process controlled by power of the ultrasonic processor, time of treatment, temperature and amount of sample. As a consequence of this particle-size reduction the surface area increases sharply with sonication time. The addition of water in ultrasound-assisted extraction produce high yield of rebaudioside $\mathrm{A}$ as comparing with classical methods like maceration and heat extraction.

\section{Acknowledgements}

This study was supported by the National Key Technology R\&D Program in the 12th Five year Plan of China (2011BAD23B03), the Key Project of National Natural Science Fund (31230057), the Open Research Project of Key Laboratory of Carbohydrate Chemistry and Biotechnology Ministry of Education (KLCCB-KF201206) and the Natural Science Foundation of Jiangsu Province (BK2011149).

\section{References}

[1] Puri M., Sharma D., Tiwari AK., "Downstream processing of stevioside and its potential Applications,” Biotech adv, 29. 781-79. 2011.

[2] DuBois GE., Stephenson RA., "Diterpenoid sweeteners. Synthesis and sensory evaluation of stevioside analogs with improved organoleptic properties,” J Med Chem, 28. 93-98. 1985.

[3] Wang, L., Weller, CL., "Recent advances in extraction of nutraceuticals from plants," Trends Food Sci Tech, 17. 300-312. 2006.

[4] Kim, J., Choi, Y.H., Choi, Y-H: Use of stevioside and cultivation of Stevia rebaudiana in Korea, A. Douglas Kinghorn, 2002, 196

[5] Mizutani, K., Tanaka, O., "Use of Stevia rebaudiana sweeteners in Japan, Stevia, the Genus Stevia,” Med Aromat Plants, 19. 178-195. 2002.

[6] Shetty, P., "Public health: India's diabetes time bomb,” Nature, 48. 514-516. 2012.

[7] Geuns, J., “Stevioside,” Phytochemistry, 64. 913-921. 2003.

[8] Fronza, D., Folegatti, M.V., "Water consumption of the stevia (Stevia rebaudiana (Bert.) Bertoni) crop estimated through microlysimeter,” Sci Agr, 60, 595-599. 2003. 
[9] Rahi, P., Pathania, V., Gulati, A., Singh, B., Bhanwra, R.K., Tewari, R., "Stimulatory effect of phosphate- solubilizing bacteria on plant growth, stevioside and rebaudioside-A contents of Stevia rebaudiana Bertoni,” App Soil Ecol, 46. 222-229.2010.

[10] Madan, S., Ahmad, S., Singh, G., Kohli, K., Kumar, Y., Singh, R., Garg, M., "Stevia rebaudiana (Bert.) Bertoni - a review,” Indian J Nat Prod Resour, 1. 267-286. 2010.

[11] Das, K., Dang, R., Shivananda, T., "Influence of bio-fertilizers on the availability of nutrients $(\mathrm{N}, \mathrm{P}$ and $\mathrm{K})$ in soil in relation to growth and yield of Stevia rebaudiana grown in South India,” Int J Appl Res Nat Prod, 1. 20-24. 2008.

[12] Nabors, L.O.B., Alternative sweeteners, 2012. CRC Press

[13] Mason, T., Power ultrasound in food processing-the way, Ultrasound in food processing, 1998, 105

[14] Mulet, A., Benedito, J., Golás, Y., Cárcel, J.A., "Noninvasive ultrasonic measurements in the food industry,” Food Rev Int, 18. 123-133. 2002.

[15] Mason, T., Paniwnyk, L., Lorimer, J., "The uses of ultrasound in food technology,” Ultrason Sonochem, 3. 253-260. 1996.

[16] Condón, S., Raso, J., Pagán, R., Barbosa-Cánovas, G., Tapia, M., Cano, M., "Microbial inactivation by ultrasound," Novel food processing technologies, 423-442. 2005.

[17] Neppiras, E., “Acoustic cavitation series: part one: Acoustic cavitation: an introduction,” Ultrasonics, 22. 25-28. 1984.

[18] Henglein, A., "Sonochemistry: historical developments and modern aspects," Ultrasonics, 25. 6-16.1987.

[19] Gasmalla, M.A.A., Yang, R.A., Amadou, I., Hua, X., "Nutritional composition of Stevia rebaudiana Bertoni leaf: Effect of drying method,” Trop J Pharm Res, 13. 61-65.2014.

[20] Association of Official Analytical Chemists International. Official Methods of Analysis of the Association of Official Analytical Chemists International 17th edn., Arlington, VA, USA, 2000.

[21] ICUMSA (International Commission Uniform Methods of Sugar Analysis). Method book1st supplement. (1998).

[22] Kimball, D.A., Citrus processing: a complete guide, Aspen Gaithersburg, MD, 1999, 450.

[23] Buera, M., Lozano, R., Petriella, C., "Definition of colour in the non-enzymatic browning Process,” Die Farbe, 32. 318-322.1986.

[24] Guerrero, S., Alzamora, S., Gerschenson, L., "Optimization of a combined factors technology for preserving banana purée to minimize colour changes using the response surface methodology,” J food eng, 28. 307-322.1996.

[25] Castañón, X., Argaiz, A., Lopez-Malo, A., "Effect of storage temperature on the microbial and color stability of banana purée with addition of vanillin or potassium sorbate/Efecto de la temperatura de almacenamiento en la estabilidad microbiológica y en el color del puré de plátano con la adición de vainillina o sorbato de potasio,” Food Sci Technol Int, 5. 51-58.1999.

[26] Mishra, P., Singh, R., Kumar, U., Prakash, V., "Stevia rebaudiana - A magical sweetener,” Global J Biotechnol Biochem, 5. 62-74. 2010.

[27] Tadhani, M., Subhash, R., "Preliminary Studies on Stevia rebaudiana Leaves: Proximal Composition, Mineral Analysis and Phytochemical Screening,” J Medical Sci, 6. 321-326. 2006.

[28] Rai, C., Majumdar, G.C., De, S., "Primary Clarification of Stevia Extract: A Comparison Between Centrifugation and Microfiltration,” Separ Sci Technol, 48. 113-121. 2013.

[29] Kaushik, R., Pradeep, N., Vamshi, V., Geetha, M., Usha, A., "Nutrient composition of cultivated Stevia leaves and the influence of polyphenols and plant pigments on sensory and antioxidant properties of leaf extracts,” J Food Sci Technol. 47. 27-33. 2010.

[30] Esmat Abou-Arab, A., Azza Abou-Arab, A., Ferial Abu-Salem, M.,"Physico-chemical assessment of natural sweeteners steviosides produced from Stevia rebaudiana bertoni plant," African J Food Sci, 4. 269-281. 2010.

[31] Serio, L., "La Stévia, une alternative au sucre et à l'aspartame,” Phytothérapie, 8. 26-32. 2010.

[32] Gisleine, E.C, Abdol, H.A, Caudio, C.A., Letícia de, A.F.F., Gilson, T., Mirian, H.T.,Wilson, E.F., Roberto, B.B., "Investigation of the tolerability of oral Stevioside in Brazilian hyperlipidemic Patients,” Brazilian Arch Biol Technol,” 49. 583587. 2006.

[33] Atanassova M. Christova-Bagdassarian V. Determination of Tannins Content byTitrimetric Method for Comparison of Different Plant Species, Journal of the University of Chemical Technology and Metallurgy.2009; 44: 413-415.

[34] Genovese, D., Elustondo, M., Lozano, J., "Color and cloud stabilization in cloudy apple juice by steam heating during crushing,” J Food Sci, 62. 1171-1175. 1997.

[35] Balaghi, S., Mohammadifar, M.A., Zargaraan, A., "Physicochemical and rheological characterization of gum tragacanth exudates from six species of Iranian Astragalus,” Food Biophys, 5. 59-71.2010.

[36] Phillips, G.O., Williams, P.A., Handbook of hydrocolloids, 2000 CRC Press.

[37] Liu, J., Li, J.W., Tang, J., "Ultrasonically assisted extraction of total carbohydrates from Stevia rebaudiana Bertoni and identification of extracts," Food Bioprod Process, 88. 215221.2010. 